\title{
Integrated Computational Methods for Traffic Emissions Route Assessment
}

\author{
Andreas Gazis Tânia Fontes Jorge Bandeira Sérgio Pereira Margarida C. Coelho \\ Department of Mechanical Engineering / Centre for Mechanical Technology and Automation (TEMA) \\ Campus de Santiago, University of Aveiro, Aveiro - Portugal \\ Telf. +351234370830
}

andreas.gazis@gmail.com, \{trfontes, jorgebandeira, sergiofpereira, margarida.coelho\}@ua.pt

\begin{abstract}
This paper focuses on the integration of multiple computational tools towards the objective of assessing emission impacts of different routes. Data from real life GPS tracks was integrated with traffic emission modelling for multiple pollutants $\left(\mathrm{NO}_{\mathrm{x}}, \mathrm{HC}\right.$, $\mathrm{CO}$ and $\mathrm{PM}_{10}$ ) to investigate different routing strategies. The main conclusion is that different pollutants dictate different best routes. Hence, strategies for assigning relative weights to pollutants are devised in order to be able to select the best environment-friendly route.
\end{abstract}

\section{Categories and Subject Descriptors \\ E.1 [Data Structures]: Graphs and Networks}

J.2 [Physical Sciences and Engineering]: Engineering

I.6.6 [Simulation Output Analysis]

\section{General Terms}

Algorithms, Measurement, Performance, Experimentation, Human Factors

\section{Keywords}

Traffic, emissions, data integration, eco-routing.

\section{INTRODUCTION AND OBJECTIVES}

With the increased adoption of GPS and mobile computing, increasingly sophisticated routing solutions are becoming mainstream. Current commercial applications typically focus on shortest path or minimum travel time, while networked platforms allow for real time congestion data to adjust these results. However, research into adding environmental factors to route planning had been going on before the recent technological leap: in 1993, Tzeng and Chen [1] suggested a methodology for solving the problem of optimizing between the different interests of three distinct groups: road users (typically concerned with the shortest travel time), local population (concerned about the impacts of pollution) and government (concerned with shortest travel distance).

Ericsson et al. [2] studied the tradeoff between a navigation system based on $\mathrm{CO}_{2}$ emissions rather than shortest distance or

Permission to make digital or hard copies of all or part of this work for personal or classroom use is granted without fee provided that copies are not made or distributed for profit or commercial advantage and that copies bear this notice and the full citation on the first page. To copy otherwise, or republish, to post on servers or to redistribute to lists, requires prior specific permission and/or a fee.

ACM SIGSPATIAL IWCTS'12, November 6, 2012. Redondo Beach, CA, USA

Copyright (c) 2012 IWCTS ISBN 978-1-4503-1693-4/12/11...\$15.00 time. Their results indicate that these are not necessarily served by the same route and reductions of the order of $8 \%$ can be achieved when optimising for fuel savings. Barth et al. [3] and Minett et al. [4] further elaborate on energy / fuel efficiency by investigating the performance of energy optimised routes. Minett et al. [4] and Rakha et al. [5] suggest eco-routing algorithms based on $\mathrm{CO}_{2} /$ fuel consumption. Aziz and Ukkusuri [6] investigate the tradeoff of CO vs. time.

Looking at individual pollutants, the picture becomes more elaborate. Frey et al. [7] show the effect of road grade on emissions and point out that best total fuel use and NO emissions can dictate different routes. Ahn and Rakha [8], Ferguson et al. [9] and Bandeira et al. $[10,11]$ show that different pollutants have different best routes.

What has arisen from literature review is that, regarding route choice, the large majority of studies did not used real world data on vehicle dynamic to assess different types of pollutant emissions. There is a lack of knowledge about the environmental impact of route choice, namely if the optimization of different pollutants dictate different routes.

Thus, this research focuses on identification of eco-routing issues involving multiple pollutants as criteria. The driving question has been what kind of pollutants we can realistically expect to measure or predict using current methodologies and what algorithms might be employed to tackle them. To that end, we have used a mix of real world measurements and simulation on various different platforms to form an outline of the factors involved.

\section{SETUP}

This research involved real life data collection as well as post processing on three different platforms: C\# on Visual Studio, ArcGIS and MATLAB.

The data collection involved logging GPS tracks of routes of the network at many different days and times. The considered case study was focused in the routes between Oporto and Aveiro, Portugal (Figure 1). In total, 230 trips were logged, covering $11,550 \mathrm{~km}$. These $\operatorname{logs}$ yielded high quality second by second data, useable by the Vehicle Specific Power (VSP) methodology [7] and the CORINAIR methodology [12].

The post processing work has been allocated between the platforms as follows:

- ArcGIS: GIS platform for storing, manipulating and visualizing map data;

- $\quad$ C\# (Visual Studio): numerical computing environment used to implement the emission calculations using VSP and CORINAIR methodologies; 
- MATLAB: numerical computing environment used for integration, route planning and data analysis.

The region used for the study is shown in Figure 1. It lies between the cities of Oporto and Aveiro in Portugal. The road network considered involves a mix of motorways (A1 and A29) as well as urban and national roads (N109 and IC2). A detailed route characterization can be found elsewhere $[10,11]$.

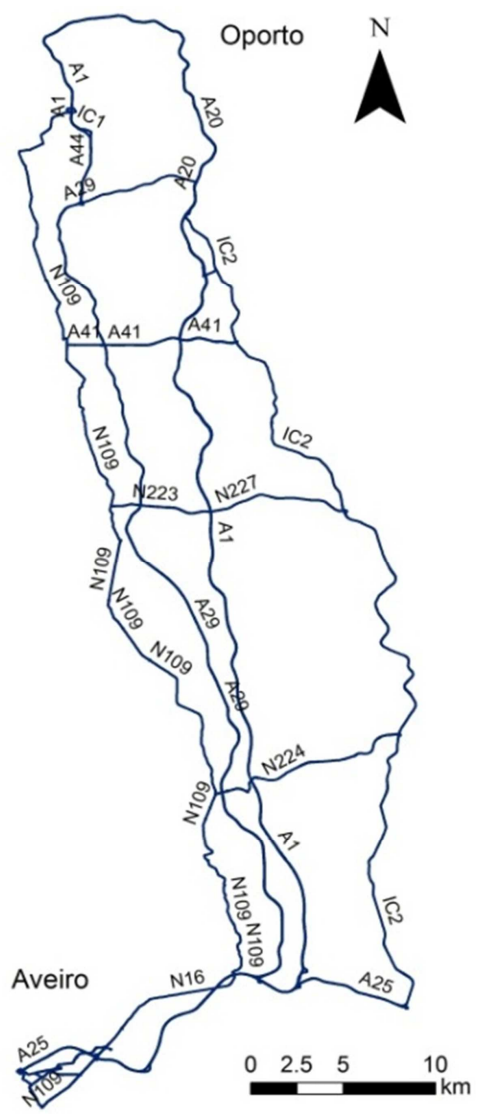

Figure 1. Region covered, between Oporto and Aveiro, Portugal.

\subsection{Emission Modelling}

Emission modelling has been implemented using two different methods: a) VSP methodology for instantaneous speeds [7, 13] and $b$ ) the CORINAIR methodology for average speeds [12]. The pollutants considered are $\mathrm{NO}_{\mathrm{x}}, \mathrm{HC}, \mathrm{CO}$ and $\mathrm{PM}_{10}$.

VSP is based on a vehicle's second by second speed, acceleration and slope and has proven to be useful in assessing emissions from several vehicle types as well as standardising comparison of emission rates across different vehicle and route types $[7,13]$. VSP values are typically grouped in combinations of $1 \mathrm{~kW} /$ ton from -50 to +50 . These values are categorised in 14 modes where each mode generates an average emission rate.

EMEP/CORINAIR is an emission factor inventory based on speed, slope and load factor. The emission factor equations are available for several types of vehicle classes. Different emission factors are available depending on the age and motor of each vehicle class.

\subsection{Data Organization}

Once all the emission data has been calculated through the C\# implementation of VSP and CORINAIR, a more complex map emerges. The original geospatial map can be visualised as a weighted graph, the weights of whose edges correspond to the lengths of each road network segment. With the addition of the emission data, each edge acquires multiple weights, depending on the criterion we might be interested in (e.g. distance, time, pollutants etc). In addition, these are also dependent on the time of day, due to factors like traffic congestion, as well as vehicle type. All these criteria are integrated as shown in Figure 2.

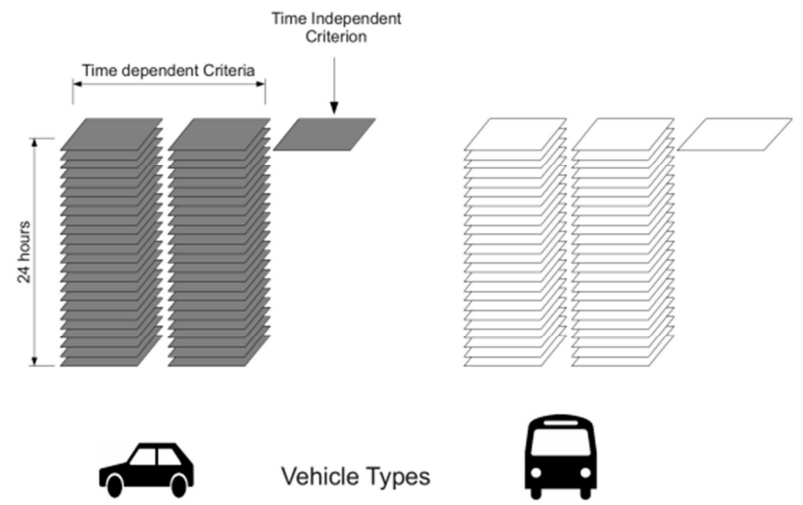

Figure 2. Overall structure of map data.

Data is organised in terms of vehicle type with one data structure per type (at this stage only gasoline light duty vehicles were considered but the algorithm is the same across any number of vehicle types). Each type contains groups of two dimensional matrices, where each matrix corresponds to the weights of the map's graph. Thus all matrices code for the same topological map but each contains different edge weight values. The data fall in two broad categories, time independent (e.g. distance) and time dependent (e.g. $\mathrm{NO}_{\mathrm{x}}$ emissions). The time dependent data contains a stack of 24 matrices (one per hour) for each criterion used.

In order for a path to be calculated, the data structure appropriate to the vehicle type in question is selected. The appropriate criterion is then chosen and, if time dependent, the matrix corresponding to the hour of day required is pulled from the stack. The criteria used for this paper are as follows:

- Time independent:

i. Distance.

- Time dependent:

i. $\quad \mathrm{NO}_{\mathrm{x}}$ (nitrogen oxides);

ii. $\quad \mathrm{CO}$ (carbon monoxide)

iii. $\mathrm{HC}$ (unburnt hydrocarbons);

iv. $\mathrm{PM}_{10}$ (particulate matter with diameter of the order of $10 \mu \mathrm{m}$ or less).

\subsection{Route Planning}

Once the data has been organised as described, route planning can be implemented using MATLAB. The planning in this research assumes that the following two conditions are satisfied: a) the vehicles using the system are few, therefore the routing has negligible impact on overall congestion and b) trips take a short enough time that conditions can be assumed to remain constant while the trip lasts. Both these are necessary in order to justify using a static matrix for each criterion. 
Given a type of vehicle, time of day and a pair of origin/destination (O/D) nodes, the appropriate matrix is used and a shortest path is calculated for each criterion using the Dijkstra algorithm ${ }^{1}$. Paths which are not unique are discarded. This implies that the final number of paths can be between one and the number of criteria used (in practice, typically a path exists that offers the best choice for at least two criteria).

The paths calculated this way offer a different mix of criteria costs which can have very different value ranges. In order to choose between them, some means of assigning relative weights must be used. We have looked at three different ways:

1. economic cost;

2. human health impact;

3. current atmospheric pollutant concentrations.

\subsubsection{Economic Cost}

This approach looks at the question of the economic cost of a pollutant once released into the air - Khattak et al. [14]. The costs associated with each pollutant are: $\mathrm{NO}_{\mathrm{x}}: \$ 4.726$ / ton; CO: $\$ 4.926$ / ton; HC: $\$ 2.247$ / ton.

While no value is given for $\mathrm{PM}_{10}$, it is an interesting starting point for tackling the comparative weighing problem.

\subsubsection{Human Health Impact}

A more comprehensive study has been carried is outlined in Eco-Indicator 99 [15], assessing, normalizing and weighting a very extensive range of substances according to various damaging effects. The effects of the pollutants considered are shown in Table 1.

Table 1. Effects of the pollutants based on Eco-Indicator 99 (unit: Disability Adjusted Life Years, DALYs).

\begin{tabular}{|l|c|c|c|}
\hline & Damage & $\begin{array}{c}\text { Normalized } \\
\text { Damage }\end{array}$ & $\begin{array}{c}\text { Weighted } \\
\text { Damage }\end{array}$ \\
\hline $\mathrm{NO}_{\mathrm{x}}$ & $8.91 \mathrm{E}-05$ & $5.75 \mathrm{E}-03$ & 1.72 \\
\hline $\mathrm{CO}$ & $7.31 \mathrm{E}-07$ & $4.72 \mathrm{E}-05$ & $1.41 \mathrm{E}-02$ \\
\hline $\mathrm{HC}(\mathrm{NMVOC})$ & $1.28 \mathrm{E}-06$ & $8.26 \mathrm{E}-05$ & $2.48 \mathrm{E}-02$ \\
\hline $\mathrm{PM}_{10}$ & $9.78 \mathrm{E}-06$ & $6.35 \mathrm{E}-04$ & $2.54 \mathrm{E}-01$ \\
\hline
\end{tabular}

The methodology involved in assigning these values contains a very exhaustive number of factors. In this study, we look at the possible results of using these as weights for our criteria.

\subsubsection{Current Atmospheric Pollutant Concentrations}

A rather interesting way of assigning weights has to do with real time conditions in the region of the trip. Pollutant concentration limits have human health impacts implicit in their values. By looking at the real time conditions, weights can be assigned to the vehicle's predicted emissions. An important consideration is that the contribution due to traffic has to be factored into the weights, e.g. if the vehicle emits primarily pollutant $X$ which is at $90 \%$ of its limit value but the concentration of $X$ is $99 \%$ due to local industry and only $1 \%$ due to traffic, the weight needs to be adjusted accordingly.

\footnotetext{
${ }^{1}$ We have used the graphshortestpath function of MATLAB's Bioinformatics Toolbox which offers the Dijkstra, BellmanFord, Breadth-first and Acyclic algorithms. Of these, Dijkstra and Bellman-Ford return best results.
}

\section{RESULTS}

Given the road network in question we have selected an Origin/Destination $(\mathrm{O} / \mathrm{D})$ pair at its farthest extremes, the origin is in the city of Oporto and the destination in the city of Aveiro. Routes connecting the O/D have to negotiate all types of roads represented in this network. The origin is connected to an urban motorway while the destination to urban streets and the section in between to national roads. Figure 3 shows the predicted emissions of the different pollutants for a light passenger gasoline vehicle at 9 AM. Thicker lines indicate higher predicted emissions of a pollutant for a given network segment.

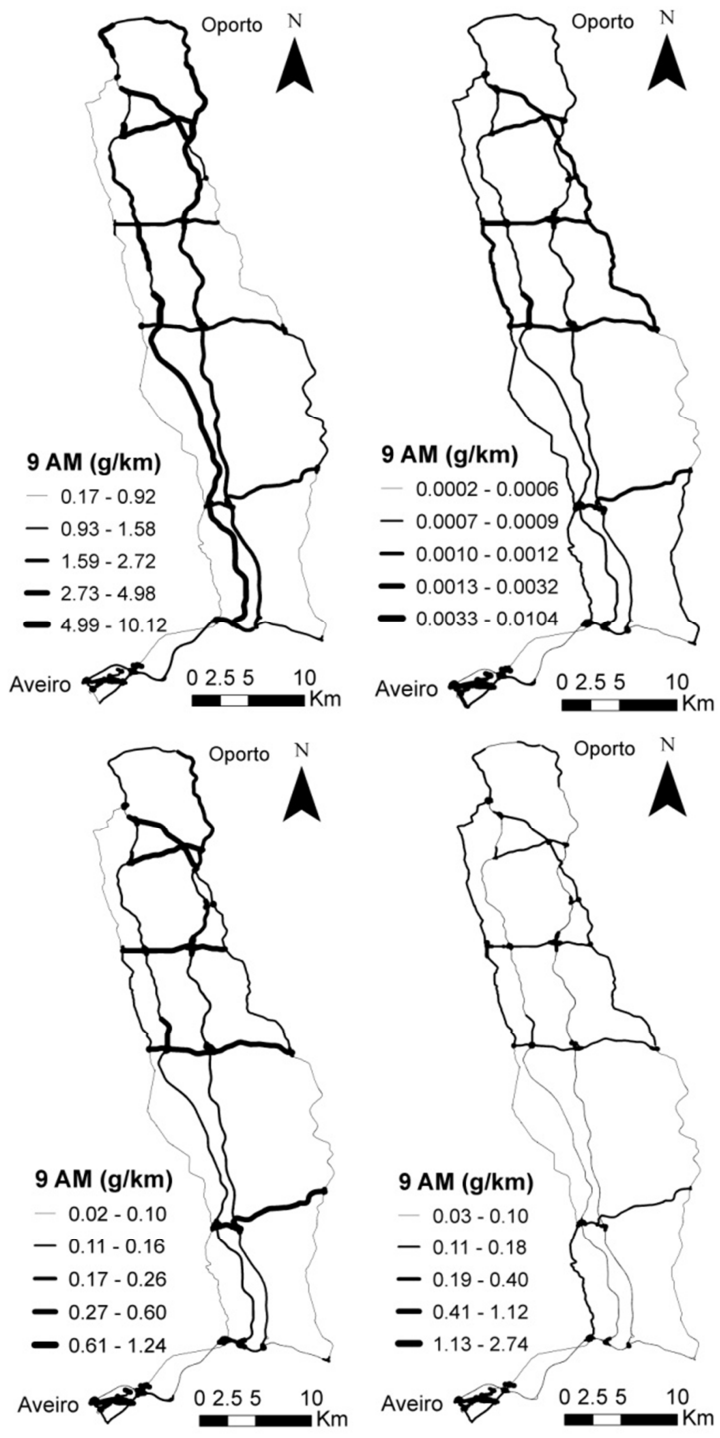

Figure 3. Pollutant estimations for $\mathrm{NO}_{\mathrm{x}}, \mathrm{CO}, \mathrm{HC}$ and $\mathrm{PM}_{10}$ at 9 AM.

Figure 4 shows the best paths for the different criteria. Note that, while there are 5 criteria ( 4 pollutants and distance), there are only 4 best paths. This is because HC and PM have the same best path (path 4), while the path for best distance (path 1) does not coincide with a best path for any pollutant. 


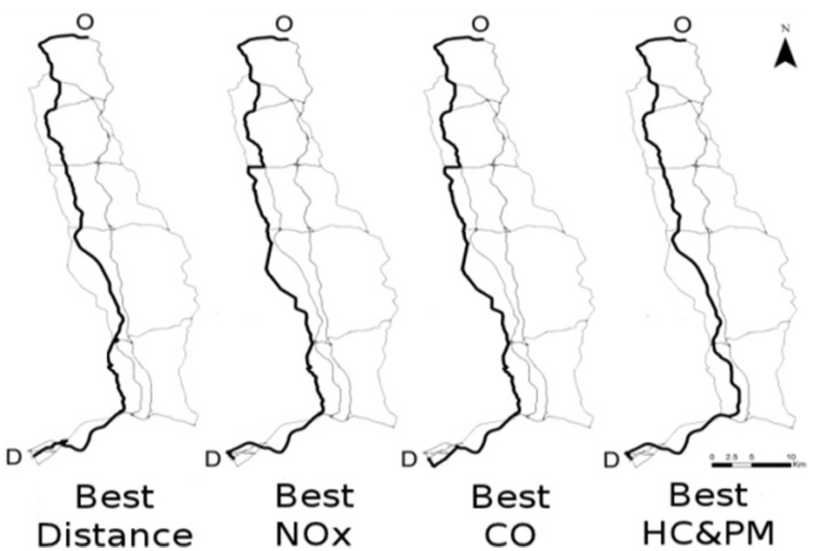

Figure 4. Best paths for various criteria at 9 AM.

The relative values for the criteria are shown in Figure 5, where each criterion is expressed as a percentage of its best (lowest) value. Thus, we can see that distance varies very little across the paths. The longest path (2) is only 3\% longer than the shortest path (1). In contrast, the highest variability among the pollutants is exhibited by $\mathrm{CO}$, whose worst value (at path 4 ) is $93 \%$ higher than its best (path 3 ). The lowest variability among the pollutants is exhibited by $\mathrm{NO}_{\mathrm{x}}$, whose worst value (path 1) is $10 \%$ higher than its best (path 2).

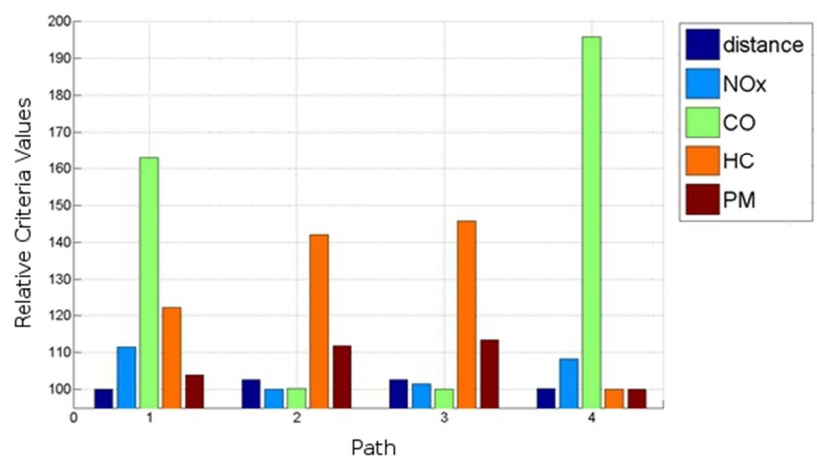

Figure 5. Relative values of the criteria expressed as percentages of their lowest value.

To answer the question of which of these paths a vehicle should actually take, these results must somehow be compared. The first comparison strategy will be based on the pollutant economic cost. These are calculated by multiplying the mass value of each pollutant by the corresponding cost value of section 0 . The results are shown in Figure 6.

In this case, each bar is a path and each pollutant a different coloured segment of the bar. The top graph shows the mass values of the emissions, while the bottom graph shows how these translate in terms of economic costs. Since the graphs are stacked, the length of each bar is the sum of its parts, therefore the best performing path equates to the shortest bar.

In mass terms (top graph), $\mathrm{CO}$ dominates while $\mathrm{NO}_{\mathrm{x}}$ and $\mathrm{HC}$ are roughly comparable. When translated in economic terms, the weights of $\mathrm{CO}$ and $\mathrm{NO}_{\mathrm{x}}$ are very close (see section 2.3.1), whereas the weight of $\mathrm{HC}$ is less than half of those. Therefore overall, $\mathrm{CO}$ remains the dominant criterion, with $\mathrm{NO}_{\mathrm{x}}$ a distant second and $\mathrm{HC}$ almost negligible. In this context, paths 2 \& 3 (optimized for $\mathrm{NO}_{\mathrm{x}}$ and $\mathrm{CO}$, respectively) offer very similar best routes.
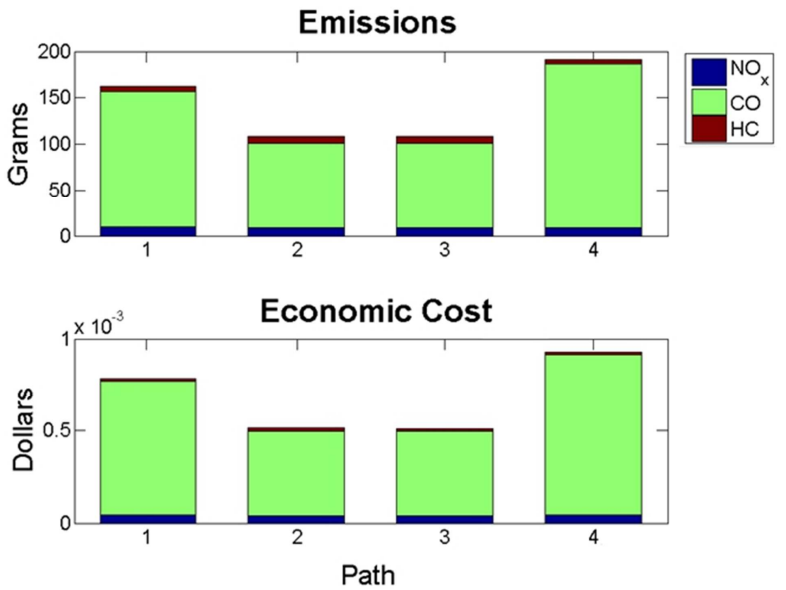

Figure 6. Economic costs of $\mathrm{NO}_{\mathrm{x}}, \mathrm{CO}, \mathrm{HC}$ for different paths.

The next comparison strategy is based on health impact as laid out in Eco-Indicator 99 (see section 2.3.2). This includes all of the pollutants in our study. The values for all pollutants and paths are shown in Figure 7. The difference between this graph and the top graph of Figure 6 is the addition of $\mathrm{PM}_{10} . \mathrm{PM}_{10}$ levels are much lower than the other pollutants (of the order of 100 times lower than HC). Since they are not visible on a linear scale, (left) they are shown more clearly on a $\log _{10}$ scale graph (right).
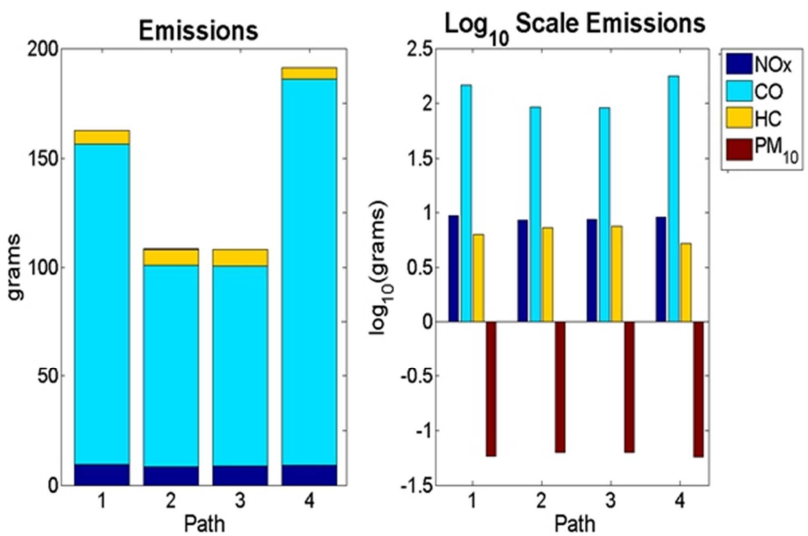

Figure 7. Absolute values for $\mathrm{NO}_{\mathrm{x}}, \mathrm{CO}, \mathrm{HC}, \mathrm{PM}_{10}$ for different paths.

Using the weights of Table 1 on these values, the health impacts can be calculated as shown in Figure 8 by multiplying the mass value of each pollutant with the corresponding damage value of Table 1. Again, a $\log _{10}$ scale is used on the right to help visualise values too low to be discernible on the linear scale (HC and $\left.\mathrm{PM}_{10}\right)$.

What is interesting in this case is that all of the three weight sets of the Eco-Indicator 99 methodology almost completely remove the dominance of $\mathrm{CO}$ and replace it with $\mathrm{NO}_{\mathrm{x}}$, while $\mathrm{HC}$ and $\mathrm{PM}$ become negligible. Because the variation in $\mathrm{NO}_{\mathrm{x}}$ among the paths is lower than in $\mathrm{CO}$ (the worst path for $\mathrm{NO}_{\mathrm{x}}$ (path 1) is only $10 \%$ worse than the best (path 2), whereas the worst path for $\mathrm{CO}$ is 
92\% worse than the best, see Figure 5), the overall variation among the paths is lowered. Still, paths $2 \& 3$ outperform the others.

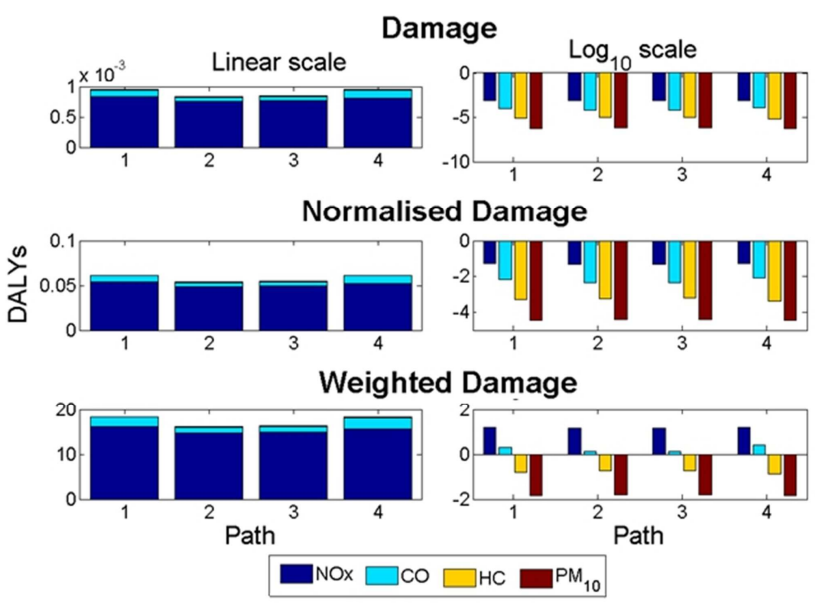

Figure 8: Health impact of $\mathrm{NO}_{\mathrm{x}}, \mathrm{CO}, \mathrm{HC}, \mathrm{PM}_{10}$ for different paths.

The final strategy we will look at has to do with current atmospheric pollutant levels. For this example, air pollution levels in the city of Aveiro ${ }^{2}$ on the $16^{\text {th }}$ of July 2012 were selected. The historical data available in this case are $\mathrm{NO}_{2}, \mathrm{CO}$ and $\mathrm{PM}_{10}$.

On this day, $\mathrm{NO}_{2}$ was at $17 \%$ of its limit value, while $\mathrm{CO}$ and $\mathrm{PM}_{10}$ were at $2.8 \%$ and $68 \%$, respectively. Figure 9 shows strategies based on these values.

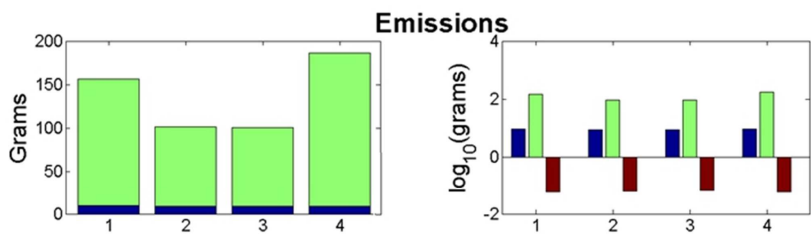

Trip costs based on pollutant concentrations

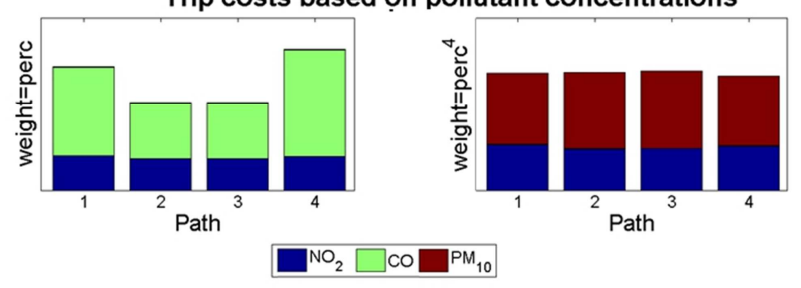

Figure 9. Relative impacts for different paths of $\mathrm{NO}_{2}, \mathrm{CO}$ and $\mathrm{PM}_{10}$ with weights based on current concentrations.

In this case, there is again the most abundant pollutant, $\mathrm{CO}$ along with $\mathrm{NO}_{2}$ (for the purpose of this section we equate our $\mathrm{NO}_{\mathrm{x}}$ estimation with $\mathrm{NO}_{2}$ ) but, instead of $\mathrm{HC}$ (which is generally of the same order of magnitude as $\mathrm{NO}_{\mathrm{x}}$, see Figure 7) there is $\mathrm{PM}_{10}$. Similar to Figure 7, this has too low a value to be visible on a linear graph (top left) so a $\log 10$ graph has been included (top right).

Two straightforward weighting strategies have been employed

\footnotetext{
${ }^{2}$ Current and historical data were obtained through the QUALAR website, which shows air quality across Portugal: http://www.qualar.org/
}

here. In the first case (bottom left) the weights are taken directly from the limit value percentages (e.g. $0.17,0.028$ and 0.68 for $\mathrm{NO}_{2}, \mathrm{CO}$ and $\mathrm{PM}_{10}$ respectively). In this case, there is a slight increase in the importance of $\mathrm{NO}_{2}$ relative to $\mathrm{CO}$ and $\mathrm{PM}_{10}$ becomes noticeable in the linear graph. However, $\mathrm{CO}$ still dominates the sum, making paths $2 \& 3$ (corresponding to best $\mathrm{NO}_{\mathrm{x}}$ and best $\mathrm{CO}$ respectively) the highest ranked.

This picture can be more heavily biased towards the pollutants closer to their limit by raising the weights to some exponent. To illustrate this, the bottom right graph shows the same picture but, in this case, the percentages have been raised to the $4^{\text {th }}$ power. In this extreme case, the effect of $\mathrm{CO}$ becomes negligible and $\mathrm{PM}_{10}$ becomes the dominant criterion. This leads to path 4 (best HC \& $\mathrm{PM}_{10}$ ) becoming the highest ranked path.

\section{CONCLUSIONS}

The main objective of this research has been to integrate multiple methods in order to identify the best routes based on multiple pollutants present in traffic emissions. This has been achieved as follows:

Emissions data has been estimated for multiple pollutants based on real life GPS tracklogs, and VSP and CORINAIR models. Using these, we have shown that optimising for different pollutants often dictates different routes. Basing a decision on these results requires some strategy of assigning weights to these pollutants so they become comparable. Three such strategies have been tried: i) based on economic costs ii) based on health impacts according to Eco-Indicator 99 and iii) based on real time atmospheric pollutant concentration levels.

The first method is more suited to a theoretical planning discussion on how to mitigate the effects of pollution. For the single vehicle type and route discussed here, the results indicated that $\mathrm{CO}$ is the most costly pollutant, with $\mathrm{NO}_{\mathrm{x}}$ being second at some 10 to 20 times cheaper depending on path (Figure 6).

The second strategy is more suited to an offline decision making application. In the absence of current data for the region of interest, a lookup table of the impacts of a small number of pollutants makes extremely modest memory requirements and can help select a route based on reasonably realistic criteria.

The third strategy is, in effect, a more general case since legal limits for each region should have impact considerations built into them (with variability for different legislation) and real-time concentration data offers the added information of which one is more important at the present time and location. The important note to be made here is that, for this method to be used appropriately, the contribution of a pollutant specifically due traffic has to be taken into account, something that needs location specific information as well as meteorological modelling. The weights of this method can be further combined e.g. two pollutants, both at $50 \%$ of their limit (strategy 3 ) but one being twice as harmful as the other (strategy 2) yielding adjusted weights to bias the decision towards the least harmful.

This area of research has a lot of potential, especially given the promise of smart vehicles, either through the use of nomadic devices or next-generation V2X technologies. A big problem of the real-time pollutant concentration strategy is that, from a real-time measuring station's point of view, the contribution to a pollutant due to traffic is unknown. This information is hard to calculate locally, since it is dependent on the type of activities (e.g. industry, shipping etc) in an area as well as meteorological patterns. However, it is not unknowable, especially for large urban centres where pollution forecasting is already a reality. The processing demanding task of simulating the interaction of the 
emissions associated with various types of human activity can be centralised. Then, routing applications can query a central database on the levels of the type of pollutants associated with their proposed trip and get lists of weights for various times and locations.

This assumes very little data traffic and leaves the details of the route planning to the querying program. In the absence of connectivity, a static look-up table of weights, as in the case of Eco-Indicator 99, can be used for the same purpose.

\section{FUTURE WORK}

This paper is strictly descriptive of the methodology, only investigating one type of vehicle, at one time of day (implying a particular congestion level) and one O/D pair. Next steps will involve expansion to multiple O/D pairs, vehicle types and congestion levels. Further integration can add microscale simulation, calibrated via experimental data, to produce realistic synthetic trajectories. These can then be treated via the VSP methodology to yield realistic extra emission data for use in large scale statistical analyses in order to refine the routing strategies.

\section{ACKNOWLEDGMENTS}

This work was partially funded by FEDER Funds through the Operational Program "Factores de Competitividade COMPETE" and by National Funds through FCT - The Portuguese Science and Technology Foundation within the projects PTDC/SEN-TRA/113499/2009 and PTDC/SENTRA/115117/2009, and FLAD - Luso American Foundation (for the Project 91-03/2010, within the program FLAD/NSF "Project-USA: Networks and Partnerships for Research"). J. Bandeira also acknowledges the support of FCT for the Scholarship SFRH/BD/66104/2009. The feedback of Prof. Asad Khattak (Old Dominion University) was mostly appreciated.

\section{REFERENCES}

[1] Tzeng, G.H., and Chen, C.H., 1993. Multiobjective decisionmaking for traffic assignment. IEEE Transactions on Engineering Management, 40, 2 (May 1993), 180-187.

[2] Ericsson, E., Larsson, H., and Brundell-Freij, K. 2006. Optimizing route choice for lowest fuel consumption Potential effects of a new driver support tool. Transportation Research Part C: Emerging Technologies, 14, 6 (December 2006), 369-383. DOI = http://dx.doi.org/10.1016/j.trc.2006.10.001.

[3] Barth, M., Boriboonsomsin, K., and Vu, A. 2007. Environmentally-Friendly Navigation. In Proceedings of the 2007 IEEE Intelligent Transportation Systems Conference. (Seattle, WA, USA, September 30 - October 3, 2007).

[4] Minett, C., Salomons, M., Daamen, W., Arem, B. v., and Kuijpers, S. 2011. Eco-routing: comparing the fuel consumption of different routes between an origin and destination using field test speed profiles and synthetic speed profiles. In Proceedings of the IEEE Forum on Integrated and Sustainable Transportation Systems (Vienna, Austria, June 29 - July 1, 2011).

[5] Rakha, H., Ahn, K., and Moran, K. 2011. INTEGRATION Framework for Modeling Eco-routing Strategies: Logic and
Preliminary Results. In Proceedings of the 90th Transportation Research Board Annual Meeting (Washington DC, USA, January 23 - 27, 2011), National Academies (Washington DC).

[6] Aziz, H., and Ukkusuri, S. V. 2011. Environmental Objectives within a Dynamic Traffic Assignment Framework: A Step towards Green Transportation. In Proceedings of 90th Transportation Research Board Meeting (Washington DC, USA, January 23 - 27, 2011), National Academies (Washington DC).

[7] Frey, H. C., Zhang, K., and Rouphail, N. M. 2008. Fuel Use and Emissions Comparisons for Alternative Routes, Time of Day, Road Grade, and Vehicles Based on In-Use Measurements. Environmental Science \& Technology, 42, 7 (February 2008), 2483-2489. DOI= http://dx.doi.org/10.1021/es702493v

[8] Ahn, K., and Rakha, H. 2008. The effects of route choice decisions on vehicle energy consumption and emissions. Transportation Research Part D: Transport and Environment, 13, 3 (May 2008), 151-167. DOI= http://dx.doi.org/10.1016/j.trd.2008.01.005.

[9] Ferguson, E.M., Duthie, J., and Waller, S.T. 2011. Minimizing Vehicle Emissions through Road Network Design Incorporating Demand Uncertainty. In Proceedings of the 90th Transportation Research Board Annual Meeting (Washington DC, USA, January 23 - 27, 2011), National Academies (Washington DC).

[10] Bandeira, J. M., Almeida, T. G., Khattak, A., Rouphail, N. M., and Coelho, M. C. 2012. Generating emissions information for route selection - Experimental monitoring and routes characterization. Journal of Intelligent Transportation Systems, in press.

[11] Bandeira, J. M., Carvalho, D. O., Khattak, A., Rouphail, N. M., and Coelho, M. C. 2012. A comparative empirical analysis of eco-friendly routes for peak hours. In Proceedings of 91st Transportation Research Board Meeting (Washington DC, USA, January 22 - 26, 2012), National Academies (Washington DC).

[12] EEA. 2009. EMEP/EEA air pollutant emission inventory guidebook. Technical report $\mathrm{N}^{\circ}$ 9/2009, European Environmental Agency.

[13] Coelho, M.C., Frey, H.C., Rouphail, N.M., Zhai, H., and Pelkmans, L. 2009. Assessing methods for comparing emissions from gasoline and diesel light-duty vehicles based on microscale measurements. Transportation Research Part D: Transport and Environment, 14, 2 (March 2009), 91-99. DOI= http://dx.doi.org/10.1016/j.trd.2008.11.005.

[14] Khattak, A., Wang, X., Zhang, H., and Cetin, M. 2011. Primary and Secondary Incident Management: Predicting Durations in Real Time. Report VCTIR 11-R11, Appendix F. Civil and Environmental Engineering Dept, Old Dominion University, USA. http://www.virginiadot.org/vtrc/main/online_reports/pdf/11r11.pdf .

[15] Goedkoop, M., and Spriensma, R. 2000. The Eco-indicator 99 - A damage oriented method for life cycle assessment. Methodology Report, PRé Consultants B.V. 